\title{
How civil engineers can help the UK meet the Paris Agreement on climate
}

\author{
Matthew Ives and Scott Thacker from the University of Oxford's Environmental Change Institute \\ explain how civil engineers can help to fulfil the UK's commitment to the recent Paris climate \\ agreement through strategic infrastructure intervention and new technologies.
}

The Paris Agreement on climate change entered into force in November 2016. With a call to limit the temperature to $1.5^{\circ} \mathrm{C}$ above pre-industrial levels, this global commitment could herald the beginning of the end of the so-called 'carbon age'.

In response to the Paris Agreement, the UK Committee on Climate Change released an update to its recommendations on UK climate action (CCC 2016). This acknowledged the UK's leadership in climate action while recognising the challenge in transitioning to net zero carbon dioxide emissions - a challenge in which civil engineers will feature prominently.

In this issue, Hall et al (2016) present potential pathways for meeting the UK's Climate Change Act obligations through transformation of national infrastructure systems. This work was undertaken using a National Infrastructure Systems Model (NISMOD) built by the Infrastructure Research Transitions Consortium (ITRC) and used as part of the Institution of Civil Engineer's National Needs Assessment report (ICE 2016).

\section{Significant challenges}

The analysis highlights the many significant challenges associated with meeting the UK's future infrastructure needs, including its climate action aspirations. With difficulties expected in reducing greenhouse gas emissions from agriculture and land use, much of the responsibility for reducing emissions will fall on infrastructure systems, particularly the energy sector (CCC 2012).

Planning the required infrastructure transition pathway is fraught with many challenges including the lock-in of long-lived assets, interdependencies between infrastructure sectors and complex drivers of demand, such as socio-economic growth, technology and climate change itself.

The NISMOD system was built to examine such challenges and provide pathways of interventions that perform robustly across a range of uncertain future conditions. Many of the technological options required to enable such a transition are in place or in development, but key decision points arise around significant new technologies.

\section{The required interventions}

Policies to reduce energy demand - mostly heating and lighting - are an obvious costeffective solution that can bring early reductions, with more advanced long-term solutions enabled through smart metering and household storage or fuel cells (Boardman 2012, Frontier Economics 2015).

Despite the UK having renewable resource potential to meet energy demands to 2050, issues around dispatch and intermittency for many of these resources mean key decisions must be made regarding emerging energy storage options and the use of nuclear and gas generation to ensure a resilient energy mix (ICE 2016).

Such technology choices will have implications across multiple sectors. 'Decarbonisation' of electricity, heat and transport will require coordinated planning and either hydrogen generation or carbon dioxide capture, with the potential for local impacts on the water sector (Byers, Hall et al. 2014). Meeting the ambitious goals of the Paris Agreement is also expected to require potentially expensive greenhouse gas removal technologies such as afforestation, carbon-storing materials, bioenergy or air capture with storage (CCC 2012).

\section{A call for coordinated action}

The task of planning the transition to net zero emissions has been taken up by the newly formed UK National Infrastructure Commission, which is actively engaged with ICE and ITRC to 
continue this work. Delivering on this ambitious vision will however require coordinated action from a multitude of actors across the UK - meeting challenges and providing solutions to enable the integration of technologies and coordinated commitments to realise a much lower carbon dioxide future.

Despite the magnitude of the challenges, the civil engineering community is well placed to lead on the solution, helping to enable a sustainable future for all.

\section{References}

Boardman, B. (2012). "Achieving zero. Delivering future-friendly buildings". Oxford, United Kingdom, University of Oxford's Environmental Change Institute.

Byers, E. A., et al. (2014). "Electricity generation and cooling water use: UK pathways to 2050." Global Environmental Change 25: 16-30.

CCC (2016). "UK climate action following the Paris Agreement", London, Committee on Climate Change

Frontier Economics (2015), Energy Efficiency: An Infrastructure Priority. London, UK.

Hall, J. W., et al. (2016). "Strategic analysis of the future of national infrastructure." Proceedings of the Institution of Civil Engineers - Civil Engineering [this issue].

ICE (2016). National Needs Assessment. A Vision for UK Infrastructure. London, UK, Institution of Civil Engineers.

For further information contact: Matthew Ives Tel: +44 1865275878 Email: matthew.ives@ouce.ox.ac.uk Web www.itrc.org.uk

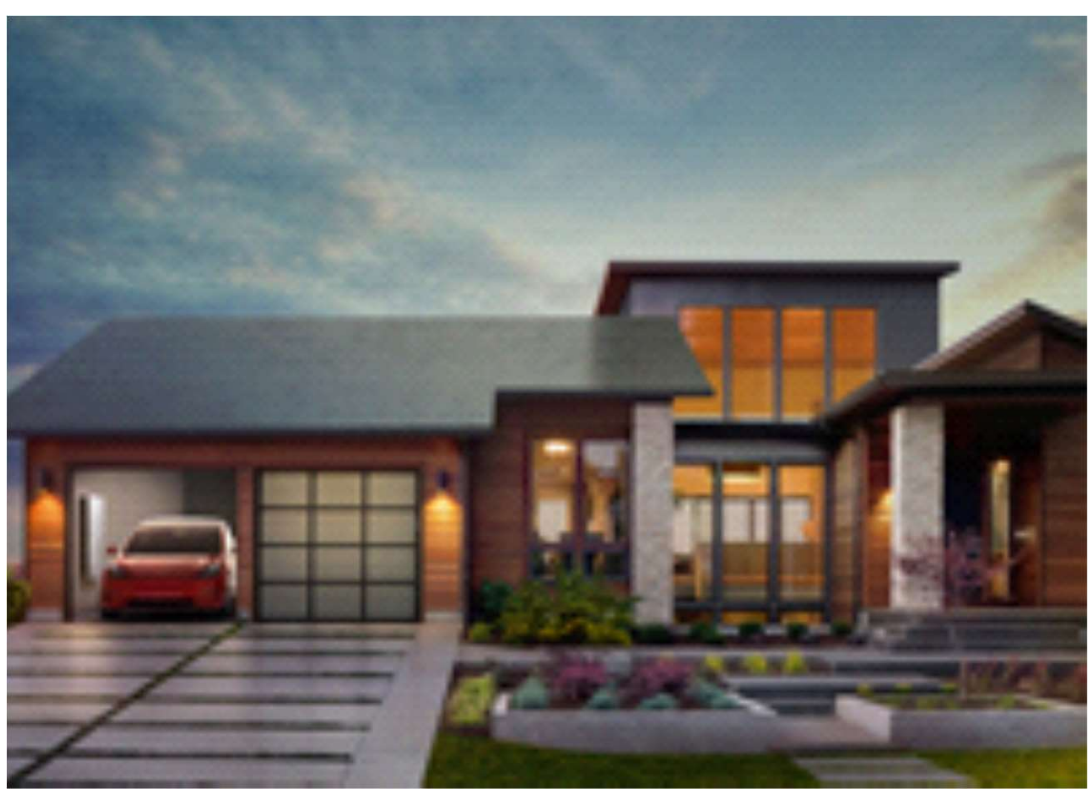

Tesla's proposed Solar Roof and Powerwall battery for homes are among the potentially gamechanging technologies that could help the UK cut its greenhouse gas emissions to zero 